\title{
Manual de zonceras educativas: Narodowski y una lectura jauretchiana de la educación
}

\author{
Manual of educational zonceras: Narodowski and a Jauretchian perspective on education \\ Mariana Chendo \\ Universidad del Salvador - Facultad de Ciencias de la Educación y de la Comunicación Social, \\ Argentina \\ marianachendo@hotmail.com
}

\section{ReSUMEN:}

El presente trabajo propone una lectura del análisis del proceso de privatización de la educación argentina realizado por Narodowski en su texto El colapso de la educación (2018) desde dos ejes hermenéuticos del pensamiento de Arturo Jauretche: la zoncera y el medio pelo. En tal sentido, realizaremos un movimiento en cuatro pasos: una presentación de la zoncera como sistema, junto con el ejercicio de la sospecha como método; la aplicación de la zoncera al proceso de privatización educativo descripto por Narodowski; la aplicación del medio pelo a la función del sector medio en dicho proceso; el desarrollo de la hipótesis de Narodowski de una política de Estado como lógica subyacente a las zonceras. En la mirada de ambos autores, intentaremos dar cuenta del concepto de lo público.

Palabras Clave: Zoncera, Medio pelo, Privatización, Público.

\section{Abstract:}

In this paper, we will try a reading of the analysis of the process of privatization in argentinian education carried out by Narodowski in his text The Collapse of Education (2018) from two hermeneutical axes of Arturo Jauretche's thought: zoncera and medio pelo. In this sense, we will make a movement in four steps: a presentation of the zoncera as a system, together with the exercise of suspicion as a method; the application of zoncera to the process of educational privatization described by Narodowski; the application of medio pelo to the function of the middle sector in that process; the development of Narodowski's hypothesis of a state policy as the logic underlying the zonceras. In the eyes of both authors, we will try to account for the concept of public.

KeYWORDS: Zoncera, Medio pelo, Privatization, Public.

"De este modo, la debilidad de nuestra inteligencia y la perversidad de nuestra voluntad se sostienen mutuamente."

Arthur Schopenhauer, El arte de tener siempre razón

"Descubrir las zonceras que llevamos adentro es un acto de liberación." Arturo Jauretche, Manual de zonceras argentinas

\section{INTRODUCCIÓN}

Arturo Jauretche propone pensar lo propio desde una hermenéutica de la zoncera. En el presente trabajo comprendemos la zoncera en tanto sistema y la sospecha en tanto el ejercicio de su interpretación, como el modo argentino de una "doctrina del prejuicio", fundamento genuino de una epistemología crítica argentina. Emparentada la zoncera al prejuicio y la sospecha al desvelamiento de su lógica oculta, Jauretche queda ligado a una tradición crítica kantiana que asienta el prejuicio en la pereza de una razón heterónoma y dependiente. En tal sentido, desandar los prejuicios será mostrar las dependencias de los sentidos naturalizados como propios, las verdades asumidas como ciertas, los valores repetidos como dogmas. En línea jauretchiana, el único pensar propio es el que parte de una mirada suspicaz, desconfiada de la pretendida normalidad que nos rodea, cuestionadora del disciplinado transcurrir de las repeticiones habituales. Pensar es sospechar de lo que 
el sentido dado, las ideologías, la opinión pública, los medios de comunicación, se obstinan en presentarnos como obvio, natural, razonable; es salir a la búsqueda de la lógica que subyace debajo de lo que estamos habituados a repetir irreflexiva y acríticamente. La obra de Jauretche es una indicación de que para encontrar lo nuestro, es necesario reflexionar sobre la ajenidad de aquello que con pretendida objetividad se nos impone, evitando cualquier posibilidad de cuestionamiento. Narodowski (2018) recoge los ejes del método jauretchiano -zoncera y sospecha- para aplicarlos al largo proceso de privatización educativa en la Argentina. El resultado es un análisis que desarma esos "enunciados que se automatizan y terminan por constituirse en coartadas perfectas para la inacción” (p.16); una vez desarmados, queda al desnudo la inverosimilitud de la zoncera: sobresimplificación, indistinción de contextos, imprecisión de variables, inconsistencia teórica; desnudada la inverosimilitud, queda a la vista la lógica subrepticia que hace de la privatización educativa la más prolongada de las políticas estatales en materia de educación: beneficio costo-efectivo; evidenciada la lógica subrepticia, el enunciado sobre la escuela pública es fatal: del colapso a la indigencia; develado el enunciado fatal, Narodowski se mantiene fiel a un ejercicio hermenéutico que privilegia la invención sobre la repetición: "reinventamos o erramos" (p. 218) en una disyunción terminal donde "reinventar" es lograr la autonomía de la razón al tiempo que "errar" es prolongar la dependencia; finalmente, la cuestión está en avivarnos o quedarnos zonzos.

Proponemos, pues, una lectura en clave jauretchiana de la hipótesis de Narodowski acerca de la privatización educativa como política de Estado analizada en El Colapso de la Educación. Desarrollaremos la lectura en cuatro pasos: una breve presentación explicativa de la zoncera en tanto sistema junto al ejercicio de la sospecha como su desocultamiento; luego, aplicaremos el sistema de la zoncera al proceso de privatización educativo desarrollado por Narodowski; en tercer momento, leeremos la función del sector medio en dicho proceso bajo la óptica del medio pelo de Jauretche; finalmente, recorreremos la política estatal como lógica subrepticia a la política educativa de privatización.

La elección del juego de los autores no es caprichosa, retoma una tradición que comprende que las prácticas discursivas muestran procesos de dominación al tiempo que posibilidades de liberación; la elección de Jauretche en Narodowski permite, además, reforzar la convicción de que el lugar intelectual argentino en el pensar lo público excede las condescendencias ideológicas en beneficio de la asunción de un compromiso crítico; la posición de que "ante la exigencia de sumisión y sacrificio", la tarea del intelectual es "la irreverencia, la confrontación, la impertinencia, la indisciplina y la insumisión” (Onfray, 2002, p. 160) en el triunfo último de verdades que se acerquen a un proyecto que podamos pensar como autónomo.

\section{EL SISTEMA DE LA ZONCERA Y EL EJERCICIO DE LA SOSPECHA}

En sus Estudios lingüisticos (1976), Amado Alonso recorre el breve uso del término zonzo en España, surgido en el siglo XVII y desaparecido en el siglo XVIII; allí mismo, llama la atención sobre la supervivencia del término en todas partes donde la palabra fue exportada, particularmente en América. La acepción de los diccionarios (desabrido, soso, sin sal) proviene del cristal duro de un término que ya había entrado en desuso. Descartado por los españoles, el término zonzo vive en los americanos y triunfa en los argentinos. El misterioso término hunde su sentido en el engaño, en la historia de un mozo bellaco llamado Zonzo que se finge tonto para engañar al amo y llevarse a una de sus hijas (Correas, 2000). La zoncera no es exactamente el engaño, sino más bien el final del proceso engañoso, la instancia en que la falsedad ya se ha revestido de certeza y el engañador ha tomado su parte, y para poder sostener su parte, es necesario sostener la falsa certeza bajo el ardid del engaño. La zoncera se propaga con la lógica del mito: oralidad, rumor y repetición. Las capas de la zoncera se endurecen de boca en oído y de oído en boca, ganan espesor, se solidifican hasta fosilizarse. Fosilizadas, convertidas en prejuicio, excluyen la argumentación y actúan dogmáticamente como "un axioma introducido en la inteligencia [...] y su eficacia no depende, por lo tanto, de la habilidad en la discusión como de que no haya discusión” (Jauretche, 1973, p. 5). Instaladas culturalmente, las zonceras se mueven "con una enorme funcionalidad dentro de los proyectos políticos que 
no parten de un reconocimiento de las demandas nacionales" (Quintar, 2007, p. 86), legitiman lo hecho evitando pensar la lógica de lo real que subyace a la zoncera, construyen todo un sistema destinado a conservar el orden funcional sin presentarle ningún cuestionamiento. En tanto "sistema", la articulación de las zonceras naturaliza un sentido acrítico que gana mayor fuerza -y mayor acriticismo- a cada repetición.

"Le faltó tiempo a Bentham para ver cómo sus discípulos rioplatenses superaban a lo que se proponía combatir", dice con ironía Jauretche (1973, p. 5) refiriendo al Tratado de los sofismas políticos (2000) y, puntualmente, a lo que Bentham llama "sofismas de prejuicio" (p. 9), ese procedimiento por el cual el prejuicio se presenta como decisivo sin apelación a ningún criterio de razón: "los que, en una asamblea política, tienen gran interés en no sufrir el examen de una cuestión se esfuerzan por poner el prejuicio solo en lugar de un razonamiento" $(i d$.$) . La zoncera se corre de los órdenes lógicos, genera su propio sistema fuera$ incluso de los márgenes de la estructura lógica: no es una falacia, no es un sofisma, no es una inconsistencia, no es estrictamente inválida puesto que no sigue exactamente el esquema de premisas y conclusión, no es con precisión un entimema ni cabe cabalmente en el discurrir erístico. Pero no la comprueban los hechos, no la corroboran los datos, no la avala el criterio de razonabilidad de un sentido común razonado. La zoncera es un prejuicio instalado en el lugar de las razones; es un mozo bellaco que ha tomado el lugar del amo con el ardid del engaño y con una prepotencia tal, con tamaña insistencia, que el engaño se olvida y el olvido le trae pertenencia, legitimidad, seguridad y certeza. Descubrir las zonceras que llevamos adentro es un acto de liberación, no personal sino de lo común de un sentido que es público, ni exclusivo del amo ni del mozo bellaco.

La palabra que abre el último libro de Mariano Narodowski (2018) es colapso; un término que viene del verbo latino collabor-caer, derrumbarse-, verbo prefijado del deponente labor-deslizarse, caer resbalando-. Un co-lapso es, literalmente, el resbalón y la caída, así, en conjunción. Pero es, además, en la metáfora de su letra, un olvido -que lleva en sí el resbalón y la caída. El título del libro es El colapso de la educación, la educación en su condición de caída, en su estado de derrumbe; pero es, además, en la metáfora de su genitivo, el olvido que hay que desocultar, las capas cristalizadas que cubren de polvo el olvido, que lo respaldan, que lo enmascaran, que lo legitiman. La "pedagogía colonialista" (Jauretche, 1973) recurre a la zoncera para "robarnos el piso" (p. 37); sin el piso, ya resbalados, ya caídos, ya colapsados, hay que seguir desocultando nuestras propias zonceras, esas "frases que por utilizarse cientos de veces acaban por impregnar nuestro sentido común", pues "su naturalización impide cualquier cuestionamiento. Enunciados que se automatizan y terminan por constituirse en coartadas perfectas para la inacción” (Narodowski, 2018, p. 16). Para dejar de ser zonzo, hay que analizar la zoncera, detenerse en los enunciados ya automatizados, sospechar de cada coartada, "de lo contrario se cae en el círculo vicioso y autoritario de una tradición única que prestigia la zoncera mientras la zoncera refuerza la autoridad” (Torres Roggero, 2010, p. 77).

Después de Paul Ricoeur (2004), el ejercicio de la sospecha se vuelve posibilidad hermenéutica contra la buena conciencia restauradora de sentidos ya siempre repetidos. Sospechar no es repetir los trazos de un sentido dado, sospechar es el ejercicio de "una crítica destructora mediante la invención de un arte de interpretar" (p. 33), es descifrar las expresiones del sentido bajo la lógica de lo oculto y lo mostrado, lo simulado y lo manifiesto. La interpretación como arte de la sospecha es el ejercicio "de la verdad como mentira"(p.33), es la búsqueda de lo oculto debajo de lo cristalizado, del lapso que subyace en lo claro, en lo distinto, en lo naturalizado como cierto. El hombre de la sospecha hace, en sentido inverso, el trabajo de falsificación del hombre del ardid; "su hipótesis de trabajo tiene los mismos límites que su ángulo de ataque" (p. 34); su procedimiento es el de desmistificación. Sospechar es atacar lo naturalizado para obligar a una extensión de la conciencia, a una toma de conciencia que responde victoriosamente a las mistificaciones de lo naturalizado, de lo vuelto verdadero a fuerza de repetición falsa, de lo oculto tras el cristal soso de la zoncera.

Narodowski propone comprender el proceso de privatización educativa en la Argentina como un ardid, como un prolongado trabajo de falsificación, de anquilosamiento de la conciencia, de ocultamiento del cuerpo de sus razones. Por eso, su texto está plagado de excusas, de justificaciones, de coartadas para la inacción, 
de paradojas, de falacias, de círculos viciosos fatales; su texto está plagado de zonceras en las que insistimos como ciertas. Para cada una de ellas, Narodowski propone su desocultamiento, el ejercicio de descifrar sus expresiones con la perspicacia de una "mirada que sospecha de todas las certezas con las que insistimos" (2018, p. 25).

\section{LA PRIVATIZACIÓN EDUCATIVA Y SUS ZONCERAS ENCUBRIDORAS}

Las zonceras consisten en principios introducidos en nuestra formación, con apariencia de axiomas, “para impedirnos pensar las cosas del país por la simple aplicación del buen sentido” (Jauretche, 1973, p. 4). Jauretche desafía al lector a sorprenderse de haberlas oído y repetido innumerables veces sin jamás haberse detenido a reflexionarlas. Narodowski (2018) propone un ejercicio de desmontaje de las zonceras educativas que se vienen oyendo y repitiendo irreflexivamente desde los inicios del proceso de privatización de la educación en Argentina. Con la lógica de la oralidad, la propagación del rumor y la insistencia de la repetición; enunciadas por funcionarios, espectacularizadas estratégicamente por los medios de comunicación, obsecuentemente repetidas por la pasividad inercial de nuestra razón perezosa.

La pereza de la razón se origina en la conjunción de tosquedad racional y desatención a los fundamentos empíricos, produciendo una confusión entre una pretendida objetividad de lo enunciado y unos fundamentos de juicio estrictamente subjetivos; a modo de conclusión del giro, la zoncera hace pasar por objetivamente válido aquello que no es válido ni es objetivo. En el movimiento zonzo, la voluntad individual queda determinada por móviles ajenos a su propia autonomía; este último punto es el centro funcional de la zoncera: "no se trata de la mera ineficiencia de la educación, sino del deliberado propósito de que sea eficiente para los fines perseguidos por [...] los razonamientos que el aparato de la superestructura cultural maneja" (Jauretche, 1973, p. 114).

Kant, en su Critica del juicio (1907, Ak V, pp. 294-295), enumera como primera máxima de la autonomía de una razón liberada de prejuicios, el "pensar por sí mismo", el corrimiento de la repetición de un se dice que conduce a la ceguera. De manera que, arrojado el enunciado, cabe preguntarse qué coherencia racional tiene y qué fundamentos empíricos lo asisten; en el caso de la zoncera, donde la respuesta a ambas preguntas es ninguno, la tercera interrogación apunta directo al centro neurálgico del axioma zonzo: ¿qué móviles ajenos determinan la voluntad del enunciado? La respuesta a esta interrogación es el acto mismo de desvelamiento; corridos los velos, se muestra el hueso de una razón heterónoma funcional a una lógica mayor, pendular y decadente (Narodowski, 2018, pp. 138 ss.).

El sistema de las zonceras funciona como un puzzle, donde cada zoncera encastra sus costados en las piezas zonzas del prejuicio de al lado, formando un gran paisaje prejuicioso que, finalmente, hace de sostén axiomático al sistema mayor de la inacción dirigente y a la permanencia conveniente de conveniencias estatales.

"Los cambios en educación tardan veinte años en concretarse" (p. 16) es una coartada para la inacción, que encuentra su aliado en la zoncera de que "los sindicatos docentes no permiten el cambio" (p. 16), logrando la paradoja de que no importa cuál sea el plazo de concreción del cambio puesto que ningún cambio es posible. La repetición de los enunciados fortifican el marco excusatorio de la parálisis de un sistema educativo paralizado.

El proceso de privatización educativo está blindado por el metal duro de las zonceras que lo recubren, evitando reflexionar sobre las razones objetivas, los datos empíricos y las hipocresías individuales que corren debajo del blindaje zonzo. La escuela privada de la vuelta "es mejor" que la pública de al lado (p. 41), "las escuelas privadas son mejores, enseñan más, son de calidad más alta” (p.52); la réplica de lo óptimo y la moda de las calidades construye -desde el desconocimiento, el automatismo y la estrategia mediática- el aval a un acuerdo generalizado de "estandarización” de países cuyo enfoque es predominante. 
"El cumplimiento del calendario escolar y la ausencia de paros en la privada es la clave" y sus derivadas (p. 51 ss.) quedan cristalizadas en la identificación entre escuela pública y escuela cerrada, pasando por las subidentificaciones de huelga docente y maestro ausente. Toda esta línea de enunciados repetitivos queda encriptada en el dispositivo "paritaria" como la variable explicativa del proceso de privatización educativa. Ningún dato valida esta convicción y, muy por el contrario, el incremento de la inscripción privada aumenta independientemente de la mayor o menor conflictividad laboral por parte de los docentes de cada provincia. Sin embargo, la convicción persiste y el dispositivo "paritaria" es el más encendido así entre los estacionales especialistas de panel como en los fulgores sapienciales de sobremesa.

"El crecimiento económico favorece la elección por la escuela privada" (p. 47) es una zoncera con correlación estadística entre los ciclos de bonanza económica y el aumento de matrícula privada. Sin embargo, y a pesar de la estadística, tiene el engaño de un sofisma, porque cuando la presión impositiva aumenta sobre los sectores medios, las familias siguen decidiendo pagar por la educación a pesar de la obligación del Estado de proveerla gratuitamente. Considerar que el dinero es el origen del fenómeno sea, tal vez, el más perjudicial de los prejuicios porque identifica en un mismo trazo fatal la escuela pública con la pobreza.

Los ribetes de las zonceras son abruptos, son desmedidos, son irracionales; aún así, nos atraviesan. Deberíamos preguntarnos cuántas veces nos hemos escuchado repitiendo que "en Argentina el 50\% de los adolescentes de 15 años no entiende lo que lee" (p. 98), cuántas veces hemos escuchado en silencio que "los docentes son vagos" (p. 181), que "la culpa del deterioro educacional es de los educadores mal formados, mal capacitados, desinteresados, descomprometidos, faltadores, antiguos, vagos” (p. 201). Cada vez que nos dormimos pensando en Finlandia y nos despertamos siendo Argentina, deberíamos dejarnos al asombro de nuestro ser zonzo.

El sistema de la zoncera y su desmontaje crítico sea tal vez, vía Jauretche, nuestro modo argentino de una "doctrina del prejuicio" que constituye una verdadera base de epistemología crítica. Kant (1907), a lo largo de sus Críticas, enseña que el prejuicio se halla emparentado con una culpable minoría de edad del sujeto y asimila el concepto de prejuicio a la noción de una razón pasiva opuesta a la autonomía racional, una pasividad que no busca en sí la fuente de su toma de posición. Es zonza, pues, la razón heterónoma y esclava, repetidora de lo hecho antes, de lo pensado por otro, abandonada a lo dicho siempre por no se sabe nunca quién. Salir de la zoncera es pensar por nosotros mismos, en coherencia con nosotros mismos, liberados de los prejuicios, en consonancia con un saber ampliado, consecuente, proyectual, activo. Salir de la zoncera es el ejercicio en el camino a un pensamiento autónomo, logrado a fuerza de autocrítica contra los prejuicios causados por la precipitación y asociados a la autoridad, fosilizados, convertidos en dogma. Trabajar con la zoncera es avivar a la razón para salir de una pereza funcional y dañina, así en Jauretche como en Narodowski.

\section{El MEDio PELO ARgentiNo Y LA PRIVATIZACIÓN EDUCATIVA}

La sentencia es implacable: "los protagonistas de la salida al sector privado son los sectores medios urbanos: clases medias con el capital cultural suficiente como para identificar preferencias y opciones" (Narodowski, 2018, p. 23), la clase media que hace a una "conversación pública argentina" orgullosa históricamente de su educación pública al tiempo que depositaria del futuro en la escuela privada. El grupo "medio" es definido más cultural que económicamente, "sus límites son imprecisos por cuanto la posesión del status no es concreta de naturaleza material ni materializable, sino un hecho anímico" (Jauretche, 2015, p. 191). La lógica de apariencia y pertenencia del grupo "medio" está más vinculada a la subjetividad del agente que a la posesión objetiva de status: "se elige escuela a la que va gente como uno o gente como la que uno quisiera llegar a ser" (Narodowski, 2018, p. 55). La ficción que determina el medio pelo es la imagen que uno se hace de la gente como uno, ${ }^{1}$ junto con el denodado esfuerzo por parecerse a esa gente para, finalmente algún día -si Dios quiere y la escuela acompaña-, poder ser como esa gente que es como la imagen que uno tiene de la proyección de sí mismo. La elección de la escuela privada es una pieza férrea en el engranaje de esta ficción de medio pelo. No es la clase ni la raza ni el nivel 
social lo que determina lo medio del medio pelo, sino la ficción de un status siempre más y siempre mejor que, en el caso del proceso de privatización educativa, deja a lo público en la fragilidad de un status siempre menos y siemprepeor.

La nivelación por status tiene, además, la complejidad de su estructura y su causa es ajena a las voluntades individuales. Sin embargo, la ficción de los del medio legitima el funcionamiento de los dirigentes de arriba; es norma, así en Jauretche como en Narodowski. Pero en Narodowski, los "firuletes interpretativos" en los órdenes discursivos de legitimación asumen una complejidad mayor, porque no se trata ya del industrial imitando el lenguaje del estanciero sin estancia, no se trata ya del balbuceo de vocal cerrada de la Sociedad Rural o el Jockey Club; en el caso de la privatización educativa, se trata de un parecer público pero un salvarse privado, junto con el ocultamiento de esa misma salvación, sus causas y consecuencias. Un parecer público pero un salvarse privado: una "forma esencialmente híbrida que combina la tendencia a la mercantilización con procesos regulativos de control público" (Alegre, 2010, p. 1159). Se trata de la cuestión del "tropos de los comunes" en materia educativa, ${ }^{2}$ esa idea de "lo común” que Dagnino (2006) designa como "confluencia perversa": la confluencia en un mismo vocabulario de defensa de los espacios públicos y fomento de las dinámicas privatizadoras. El sector medio proclama su profunda fe en lo público mientras se fuga a lo privado, "la salida al sector privado de la educación conforma una especie de espejismo en el que las clases medias aspiran a concretar su ilusoria autosalvación, ampliando así la segregación socioeconómica entre escuelas" (Narodowski, 2018, p. 23), en una privatización que no es causa sino consecuencia de la segregación. La ficción de un gran sector de los del medio adopta los modos simbólicos de defensa de la escuela pública pero los órdenes reales de elección de la escuela privada, produciéndose como efecto el corrimiento del sector medio del debate público de la educación. Finalmente, el lenguaje jurídico es muestra cabal del proceso de legitimación: toda escuela argentina es pública, así las de gestión estatal cuanto las de gestión privada. Los medios de comunicación con sus especialistas de turno -todos ellos aparatos ideológicos del medio pelo-, juegan al engaño recíproco y paradojal de la defensa y la fuga.

A pesar de que en ambos, "los del medio" desnaturalizan su función respecto de lo público, el medio pelo de Jauretche se complejiza en la lectura que hace Narodowski de los sectores medios en el proceso de privatización educativa. La privatización de la educación es un proceso de triple trazo: restringe el espacio de lo público mientras reduce la educación a argumentos de consumo, al tiempo que beneficia la lógica costoefectiva del Estado. Este proceso, llevado al extremo, terminará conduciendo lo público a una educación de la indigencia (Narodowski, 2018, p. 49). Los sesgos de la "libertad de elección" de los sectores medios en el proceso de privatización educativa, recogen su centro del concepto de libertad individual, moderna o negativa de acuerdo a la clásica formulación de Constant (1989), retomada por Berlin (1988), según la cual "libertad política es simplemente el ámbito en que un ser humano puede actuar sin ser obstaculizado por los otros" (p. 191); los otros -se entiende- son los diferentes, los que pueden obstaculizar las igualdades de nuestras idénticas identidades. El proceso de privatización educativa es el triunfo de esta "libertad política", derrota de la diferencia originaria de lo público en nuestra educación.

Salir del "medio pelo" es tomar conciencia de cuán atravesados estamos por las ficciones del medio pelo, es desocultar los modos en que la debilidad de la inteligencia y la perversidad de la voluntad se sostienen mutuamente, es mostrar cómo nuestras hipocresías individuales convertidas en axiomas terminan por destruir lo público: cómo, convertidas en prejuicios fundantes, terminan reduciendo lo común; cómo, convertidas en zonceras, terminan siendo funcionales a la inacción de las clases dirigentes. Salir del medio pelo es sospechar del medio pelo, obligando a la conciencia a extender sus propios límites, hasta la comprensión de las complicidades que llevan de lo público a la indigencia. Sospechar de una educación de "medio pelo" es volver la vista a una genealogía de la escuela pública que en sus inicios "contribuyó a impedir el enquistamiento en colonias, al recibir en su seno a todos, en pie de igualdad, marginando las influencias nacionales de origen" (Jauretche, 2015, p. 169). La sospecha es genealogía, pero es también anticipo del destino trágico de lo público, su reducción terminal en el modo de la guetificación de las escuelas: "corralitos donde los alumnos 
tienden a ser social y culturalmente muy parecidos entre sí, privándolos [...] del contacto con el ciudadano distinto" (Narodowski, 2018, p. 41), en un entresijo donde "cada una de las razas ocupan su lugar en el palo del gallinero a la hora de dormir" (Jauretche, 2015, p. 317).

\section{DeTrás de las zonCERAS: LA PRIVATIZACIÓN EDUCATIVA COMO POLÍ́TICA DE EsTADo}

"Llevado a un extremo, el argumento consumista lleva a un absurdo: supone que si el crecimiento económico continuara, la educación pública seguiría disminuyendo hasta [...] convertirse en el [...] destino natural exclusivo de los [...] indigentes" (Narodowski, 2018, p. 49). Leer las dinámicas de privatización educativa desde la guetificación, desde los corralitos, desde palo del gallinero, es leerlas desde una categoría de "cercamiento" a la que subyace una lógica mayor, jerárquica, insolidaria y excluyente. El "cercamiento" (enclosure), cuya genealogía remite a los procesos violentos sobre "lo común" (derechos y usos) de la tierra entre los siglos XIV y XVIII, retorna con fiereza en los procesos de privatización contemporáneos, junto con su lógica de alienación. Zizek (2011) recomienda leer la tragedia de "lo común" desde la lógica antagónica exclusión-inclusión, pues el "cercamiento" es la amenaza siempre latente, siempre presente, de "lo común" de la cultura -recogiendo en "lo común de la cultura", el "capital cognitivo": la educación-. Corresponde leer la educación desde la lógica de reducción de lo público al máximo de su exclusión, desde la amenaza siempre presente de "la creación de nuevas formas de apartheid, nuevos Muros y ciudades miseria" (Zizek, 2011, p. 106); finalmente, llevar la lógica al extremo, nos dará la escuela pública de la indigencia.

Corrida la zoncera, Narodowski señala la lógica de la exclusión que subyace a la privatización; pero lo que vuelve a su pesimismo lúcido, lo que lo vuelve grave, es la mostración debajo de la mostración: corrida la exclusión una vez corrida la zoncera, Narodowski muestra los auténticos polos en juego antagónico en el proceso de privatización educativa, público $v$ s. Estado: el proceso de privatización educativa como política de estatización, la más exitosa política educativa de Estado como proceso de depauperización de la escuela pública, la más prolongada política educativa de Estado como proceso de la indigencia. Escuela pública vs. Estado, el Estado recogiendo su beneficio fiscal por cada alumno fugado a la educación privada, el Estado concentrando sus recursos en la matrícula de la escuela pública cada vez con menos alumnos, el Estado sin necesidad de invertir en la educación, de pensar en la educación, de intervenir la educación, de responsabilizarse por la educación.

La paradoja lleva al encierro y deja en nivel de igualdad todos sus flancos, igualdad de desinterés, de solapamiento, de silencio e inacción. Ningún sector político reivindicando la prolongada política educativa de privatización, la privatización educativa de gobiernos nacionales y populares, de tibios, de progresistas, de neoliberales, todos ellos aparatos ideológicos del medio pelo.

El problema que está en juego no es exactamente la "privatización endógena" (Ball y Youdell, 2007), operando difusamente para hacer del sector público una empresa, con su "equidad de logros", sus "costos compartidos", su "autonomía cooperativa”; el problema que pone en juego Narodowski en la educación argentina es el conflicto de lo político, lo político como conflicto. El uso de las palabras no es directamente proporcional a las soluciones (2018, p. 94), sino directamente proporcional a lo real del conflicto, con sus cargas políticas e ideológicas en cada diferenciación semántica; retirados de la escuela pública, los sectores medios no sólo se retiran del conflicto, sino que lo anulan, reservando sus palabras a la sola privacidad de $l o$ público de gestión privada. Narodowski lee en la educación el efecto fundamental de la privatización como política de Estado: la despolitización de la vida social, la reducción de la educación pública a una práctica de supervivencia, el anticipo del fin de una educación que sea indicador de una sociedad deseable. El repliegue de la educación al espacio privado anula la referencia propiamente política de la educación pública, porque fuga las voluntades divergentes a los sectores privados, retirando la educación al interior moral de cada persona física y al interior económico de cada persona jurídica. Los únicos actores en pie de discusión son gobierno 
y sindicatos, donde "la única condición para el acuerdo gobierno-sindicatos es que, como resultado de la negociación, no se desordene el equilibrio alcanzado en términos de costo-eficiencia" (Narodowski, 2018, p. 61). El fenómeno de colapso es estructural: caída y ocultamiento.

"Una escuela pública casi exclusiva para los pobres mientras los sectores medios y altos se autosegregan en escuelas privadas no es el indicador de una sociedad en la que queremos vivir" (p. 209). Pero es el indicador de la sociedad en que vivimos, del colapso a la indigencia.

\section{APRECIACIONES FINALES}

Lo que hace que una ideología "sea foránea, extraña o exótica, antinacional, no es su origen sino su correspondencia con la realidad nacional y sus necesidades" (Cooke, 2009, p. 155). Ciertamente, Narodowski es favorable al "neoliberalismo"; ciertamente, carga su mordacidad contra el "progresismo"; tan ciertamente como cierto es que hace justicia a una capacidad intelectual de leer las contradicciones ajenas desde las vigas que llevan sus propios ojos. Porque debajo de las pompas retóricas de favoritismos y mordacidades, el análisis del colapso es un ejercicio de sospecha y desvelamiento. Lo que se desoculta parece asumir el carácter funcional de un destino trágico: en la Argentina y en política educativa, la ideología excede el tinte de los gobiernos porque el Estado se resignifica a sí mismo en una igual línea ideológica, foránea, extraña, exótica, antinacional, destructora de lo público de la educación pública, bajo el amparo legal de lo público en su doble vertiente de gestión pública y gestión privada.

El colapso de la educación está teñido del doble temple anímico de la nostalgia del maestro y la frustración del funcionario público. Sobre el anecdotario de la frustración y la utopía de la nostalgia, Narodowski retoma una honda tradición de pensar la educación argentina desde la Argentina, de comprender la condición de su colapso desde los procesos de ocultamiento, de develar las complicidades silenciosas del medio pelo argentino -en el que, con fatal lucidez, Narodowski se incluye-, de sincerar la inacción de las clases dirigentes -de la que, en el giro de las fatalidades, Narodowski asume su parte-, de construir la posibilidad de un contramovimiento desde el ejercicio de la sospecha. Sin decirlo -tal vez sin pretenderlo-, el texto resulta de corte jauretchiano: "de la comprobación aislada de cada zoncera llegaremos por inducción [...] a comprobar que se trata de un sistema, de elementos de una pedagogía, destinada a impedir que el pensamiento nacional se elabore desde los hechos, es decir desde las comprobaciones del buen sentido" (Jauretche, 1973, p. 7). Tal vez sea indicio de que lo común del buen sentido nos sigue interpelando, aún caídos, aún colapsados, aún zonzos en la tilinguería de nuestro medio pelo argentino. Tal vez sea indicio de que el único sentido común de una educación propia es su sentido público, ni exclusivo del amo ni del mozo bellaco.

\section{REFERENCIAS}

Alegre, M. A. (2010). Casi-mercados, segregación escolar y desigualdad educativa: una trilogía con final abierto. Educação \& Sociedade, 31(113), 1157-1178.

Alonso, A. (1976). Estudios lingüisticos. Temas hispanoamericanos. Madrid: Gredos.

Ball, S. J., y Youdell, D. (2007). Privatización encubierta en la educación pública. Informe preliminar para el V Congreso Mundial de la Internacional de la Educación. Londres: Universidad de Londres, Instituto de Educación.

Bentham, J. (2000). Tratado de los sofismas politicos. Ediciones elaleph.com.

Correas, G. (2000). Vocabulario de refranes y frases proverbiales. Madrid: Castalia.

Berlin, I. (1988). Cuatro ensayos sobre la libertad. Madrid: Alianza.

Constant, B. (1989). Escritos politicos. Madrid: Centro de Estudios Constitucionales.

Cooke, J.W. (2009). Obras Completas. Peronismo y revolución. Apuntes para la militancia. La lucha por la liberación nacional. Informe a las bases. Tomo V. Buenos Aires: Colihue. 
Dagnino, E. (2006). Sociedad civil, participación y ciudadanía, ¿̇de qué estamos hablando?. En E. Isunza y A. Olvera (Coords.). Democratización, rendición de cuentas y sociedad civil: participación ciudadana y control social (pp. 223-242). México D. F.: Centro de Investigaciones y Estudios Superiores en Antropología Social-Universidad de Veracruz.

De Lissovoy, N., Means, A., J., y Saltman, K. J. (2014). Toward a New Common School movement. London: Paradigm Publisher.

Escudero, J.A. (2009). El lenguaje de Heidegger. Diccionario Filosófico 1912-1927. Barcelona: Herder.

Jauretche, A. (1973). Manual de zonceras argentinas. Buenos Aires: A. Peña Lillo Editor.

Jauretche, A. (2015). El medio pelo en la sociedad argentina. Buenos Aires: Ediciones Corregidor.

Kant, I. (1907). Gesammelte Schriften. Königliche Preußische Akademie der Wissenschaften / Georg Reimer / Walter de Gruyter / Vereinigung Wissenschaftlicher Verlager / Akademie der Wissenschaften zu Göttingen / Akademie der Wissenschaften der DDR, Berlin / Leipzig.

Lewis, T. E. (2012). Exopedagogy: On pirates, shorelines, and the educational Commonwealth. Educational Philosophy and Theory, 44(8), 845-861.

Narodowski, M. (2018). El colapso de la educación. Buenos Aires: Paidós.

Onfray, M. (2002). Cinismos. Buenos Aires: Paidós.

Quintar, J. (2007). Pensar con estaño. El pensamiento de Arturo Jauretche. Neuquén: Euduco.

Ramírez, R. (2014). La virtud de los comunes. De los paraísos fiscales al paraíso de los conocimientos abiertos. Quito: AbyaYala.

Ricoeur, P. (2004). Freud; una interpretación de la cultura. México: Siglo XXI Editores.

Schopenhauer, A. (2011). El arte de tener siempre razón. Barcelona: José J. de Olañeta Editor.

Torres Roggero, J. (2010). Dos profetas de la des-colonialidad en Argentina. En Z. Palermo (comp.). Pensamiento Argentino y Opción Descolonial. Buenos Aires: Ediciones del Signo.

Zizek, S. (2011). Primero como tragedia, después como farsa. Madrid: Akal.

\section{Notas}

1 El "uno" de Jauretche y el "uno" de Narodowski encuentran su encuadre filosófico en el das Man de la hermenéutica fenomenológica heideggeriana. La expresión sustantivada das Man es introducida por Heidegger en sus estudios de 1923 para aludir a una existencia cuya inautenticidad radica en vivir bajo el "uno impersonal". "Esta referencia a un tipo de hombre normal y corriente, esta alusión a una especie de sujeto impersonal, colectivo y anónimo, queda muy bien reflejada tanto en la expresión catalana hom como en la noción de la gente acuñada por Ortega y Gasset” (Escudero, 2009, p.127). En este sentido, el medio pelo de Jauretche y "la gente como uno" de Narodowski, remiten a la mediocridad de un sujeto indeterminado que, referido a la normalidad, no responde a nadie concreto y por nadie concreto se responsabiliza.

2 Respecto del "tropos de los comunes" y la categoría de "lo común” para repensar la educación y la escuela en el difícil entramado público-privado-común, los procesos de privatización encubierta y el lugar de Estado, cfr. De Lissovoy et al. (2014), Lewis (2012), Ramírez (2014). 